Examination of spatial working memory performance in children and adolescents with Attention Deficit Hyperactivity Disorder, combined type (ADHD-CT) and anxiety

Alasdair Vance ${ }^{1 *}$, Maite Ferrin ${ }^{2,3}$, Jo Winther $^{1}$, Rapson Gomez ${ }^{4}$

Corresponding author: ${ }^{1}$ Academic Child Psychiatry Unit, Department of Paediatrics, University of Melbourne, Royal Children's Hospital, Murdoch Children's Research Institute, Parkville VIC 3052, Australia; telephone: 6139345 4666; facsimile: 6139345 6002;email: avance@ unimelb.edu.au

${ }^{2,3}$ Maite Ferrin MD, MsC, PhD. ${ }^{2}$ Department of Child and Adolescent Psychiatry, Institute of Psychiatry. Sunshine House (Neurodevelopmental Team), 27 Peckham Road, SE5 8UH London (UK); ${ }^{3}$ Centro de Salud Mental Estella. Camino de Logroño 4, 31200 Estella- Navarra (Spain); email maiteferrin@yahoo.es

${ }^{4}$ School of Psychology, University of Tasmania; email rapson.gomez@utas.edu.au

Running Head: ADHD and anxiety, spatial working memory 


\section{Examination of spatial working memory performance in children and adolescents with Attention Deficit Hyperactivity Disorder, combined type (ADHD-CT) and anxiety}

Spatial working memory (SWM) is known to be impaired in children with ADHD-CT, whether anxiety is present or not. Yet, it remains unclear whether anxiety disorders add to the SWM impairments evident in ADHD-CT and whether these findings extend into adolescents with ADHD-CT and anxiety. Further, it is not yet known whether children and adolescents with carefully defined anxiety disorders alone, demonstrate SWM deficits. This study explored the association of SWM and its strategy and spatial span components in carefully defined children and adolescents (age 6-16 years) with ADHD-CT alone ( $\mathrm{N}=163 ; 14 \%$ female), ADHD-CT and anxiety $(\mathrm{N}=243 ; 23 \%$ female), anxiety disorders alone $(\mathrm{N}=69 ; 25 \%$ female $)$ compared to ageand gender-matched healthy control participants $(\mathrm{N}=116 ; 19 \%$ female $)$. The relationship between SWM and its strategy and span components and core ADHD-CT symptoms and anxiety symptoms were also examined. There was no evidence of an additive effect of ADHD and anxiety on SWM, strategy and spatial span deficits. But, anxiety disorders alone were associated with impaired SWM and span performance compared to healthy control participants. In contrast, strategy did not differ between children and adolescents with anxiety disorders alone and healthy control participants, suggesting that with anxiety span is the most affected component. Further, these findings were age-independent. This study concurs with and extends current influential models about the cognitive effects of anxiety on performance in the setting of ADHDCT. Clinical implications and future research directions are discussed.

Keywords: ADHD combined type, anxiety, spatial working memory, children/adolescents 

Attention Deficit Hyperactivity Disorder, combined type (ADHD-CT) is one of the most common neuropsychiatric conditions affecting children and adolescents and a major driver for referral of children and adolescents to mental health services (Merikangas, He, Burstein, Swendsen, \& Avenevoli, 2011; Polanczyk, de Lima, Horta, Biederman, \& Rohde, 2007). Anxiety disorders are similarly common, with Generalised Anxiety Disorder (GAD), Separation Anxiety Disorder (SAD), Specific Phobia (SpPh) and Social Phobia $(\mathrm{SoPh})$ the most frequently identified anxiety disorders in both epidemiological and clinical samples (Last, Hersen, Kazdin, Orvaschel, \& Perrin, 1991; Tannock 2009). Further, there is a known greater than chance association between ADHD-CT and GAD, SAD, SpPh and SoPh in clinical samples of children (Jensen, Hinshaw, \& Kraemer, 2001; Last et al. 1991), evident across key developmental stages and sociocultural groups (Biederman, Faraone, \& Mick, 1999; Schatz and Rostain, 2006). To date, there has been relatively little systematic research of the nature of this comorbid anxiety, despite its clinical importance as a potential subtype of ADHD (Jensen, Martin, \& Cantwell, 1997) and a possible moderator of stimulant medication and psychosocial treatment response (March, Swanson, Arnold, Hoza, \& Conners, 2000). ADHD-CT has also been associated with increased rates of comorbid anxiety that do not appear to decrease with increasing age (Cantwell and Barker, 1992; Vance, Barnett, Costin, Luk, \& Maruff, 2002; Wolraich, Hannah, Pinnock, Baumgaertel, \& Brown, 1996; Woolston, Rosenthal, Riddle, Sparrow, \& Cicchetti, 1989).

Working Memory (WM) comprises a verbal and spatial capacitance (storage) function as well as a manipulating function (e.g., the ability to prioritize and organize information particularly moving from low stimulus to high stimulus environments) (Kofler, Rapport, Bolden, Sarver, \& Raiker, 2010). Spatial working memory (SWM) involves the temporary storage and manipulation of visuospatial (non-verbal) 
information that is necessary for a range of more complex cognitive functions (Baddeley 1986; Barnett, Vance, Maruff, Luk, \& Costin, 2001). However, although differentiable, verbal and spatial working memory functions are deeply interrelated (Karatekin 2004). Further, recent functional neuroimaging work has demonstrated common brain regions (right parietal region BA 40 and BA 7) activated in both verbal and spatial working memory tasks (McNab, Leroux, Strand, Thorell, \& Bergman, 2008). Nevertheless, SWM and attentional abilities are known to be subserved by overlapping neural substrates, including predominantly inferior and superior parietal regions together with lateral prefrontal regions (Awh and Jonides, 2001; Postle, 2006). Recent fMRI studies suggest that SWM relies on cognitive processes associated with spatial attention, rather than involving memory per se (Postle, 2006), and thereby depends on a predominantly right-hemisphere frontal-parietal attentional system. SWM is a crucial cognitive process that may be impaired in ADHD (Martinussen, Hayden, Hogg-Johnson, \& Tannock, 2005; Vance, Silk, Rinehart, Bradshaw, \& Bellgrove, 2007; Willcutt, Doyle, Nigg, Faraone, \& Pennington, 2005). It has been proffered as a key endophenotype, along with response inhibition for ADHD (Castellanos and Tannock, 2002) and a recent meta-analysis highlights SWM, more so than verbal working memory, as a key cognitive impairment in ADHD (Gathercole and Alloway, 2006). Clinically, WM impairment remains significant, because it is associated with academic underachievement (Gathercole and Alloway, 2006) and further poor academic achievement may be related more to WM impairment than to the three ADHD core symptom dimensions (Rapport, Scanlan, \& Denney, 1999). SWM is also known to be impaired in children and adolescents with anxiety disorders, although the heterogeneous nature of anxiety disorders has led to increased variability of results (Aronen Aronen, Vuontela, Steenari, Salmi, \& Carlson, 2005; Staugaard 2010) and difficulty 
differentiating the effects of anxiety from those of depressive disorders (Ladouceur, Dahl, Williamson, Birmaher, Ryan, 2005). Further, there is emerging evidence that SWM rather than the verbal working memory domain may be more affected in healthy people who become anxious (Ikeda, Iwanaga, \& Seiwa, 1996; Koric, Volle, Seassau, Bernard, Mancini, 2011; Li, Chan, \& Luo, 2010): specifically Lavric et al. (2010) and Shackman et al. (2006) have shown that healthy people that are in an anxious aroused state evince selective disruption of SWM.

To date, there is a small literature examining SWM in children with ADHD-CT and anxiety (Bedard and Tannock 2008; Manassis, Tannock, Young, \& Francis-John, 2007; Tannock, Ickowicz, \& Shachar, 1995): The findings suggest that working memory in verbal and spatial domains is impaired in primary school age children with ADHD-CT, whether anxiety is present or not. The ADHD +/- anxiety groups were well characterised, categorically and dimensionally, although anxiety was broadly defined so known heterogeneity between different types of anxiety disorders was not addressed. Also, the authors noted the need for larger samples from a greater number of settings to be examined to replicate and extend their findings. Further, only the Manassis et al. (2007) sample included an anxiety alone group and no sample included early-mid adolescent participants. In addition, the SWM tasks used were not well constrained with respect to their brain behaviour relationships. Hence, it remains unclear whether anxiety disorders add to the SWM impairments evident in ADHD-CT and whether these findings extend into adolescents with ADHD-CT and anxiety. Further, it is not yet known whether children and adolescents with carefully defined anxiety disorders alone, demonstrate SWM deficits. Certainly, the extant literature [including Lavric et al. (2010), Shackman et al. (2006)] suggests that SWM deficits would be expected in line with established developmental temperamental models (Nigg 2000). 
Accordingly, in this study, we recruited carefully defined children and adolescents with ADHD-CT alone, ADHD-CT and anxiety, anxiety alone and age- and gender-matched typically developing participants. We examined SWM using two tasks with well constrained brain-behaviour relationships so inferences about brain regional activation could be systematically drawn from participants' behavioural performance on them. They were also relatively language free so participants' performance on them was not dependent on their facility with language. We hypothesised that SWM performance would be impaired in the ADHD-CT +/- anxiety groups and the anxiety alone group compared to the healthy control group. Further we hypothesised that the ADHD-CT groups and the anxiety alone group would not differ with respect to SWM performance.

\section{Method}

Participants

One hundred and sixty three children and adolescents, aged 6-16 years, with ADHD-CT alone (14\% female), 243 with ADHD-CT and anxiety (23\% female), and 69 with anxiety alone (25\% female), were recruited from 50 primary and secondary schools. These 475 children were screened from a total sample of 1125 children and adolescents identified by teachers and/or school support staff as having ADHD and/or anxiety difficulties who then referred them to specialized university clinics in metropolitan Melbourne (Australia), over a 5 year period (2005-2009). All 1125 young people were assessed but only 475 met the inclusion/exclusion criteria: the referred children and adolescents were all stimulant, anxiolytic and/or antidepressant medication naïve at the time of their assessment and had only received school-based individual and/or group psychosocial treatments delivered by teachers and/or school support staff. ADHD-CT (DSM-IV-TR criteria, American Psychiatric Association (APA), 2000) was 
categorically defined by the semi-structured clinical interview of their parents Schedule for Affective Disorders and Schizophrenia for school age children-present and lifetime version (K-SADS-PL) (Kaufman et al. 2000) and dimensionally by the Conners' (Conners et al. 1997) parent and teacher global index (CGI) scores of the core symptom domains of ADHD-CT being greater than 1.5 standard deviations above the mean for a given child's age and gender. Anxiety disorders were defined as GAD, SAD, SoPh and/or SpPh (DSM-IV-TR criteria, APA, 2000), diagnosed through a semi-structured clinical interview with the child's parent(s) K-SADS-PL (Kaufman et al. 2000) and by the parent (CBCL) and child (RCMAS) report of the total anxiety scores being greater than 1.5 standard deviations above the mean for a given child's age and gender (Achenbach 1991; Reynolds and Richmond 1995). A total of 280 healthy control children and adolescents were recruited from the same 50 primary and secondary schools and the absence of mental disorders was confirmed using the same categorical and dimensional approach as for the clinical cases: 116 healthy control participants (19\% female) were matched for age and gender with the 475 young people with ADHDCT and/or anxiety (see Table 1). All the children and adolescents met the inclusion criteria of living in a family home (and not in an institution) and attending normal primary and secondary schools. All had non-age corrected Intelligence Quotients above 70 (Wechsler 1991) and none had identifiable learning disorders (reading, spelling and/or maths scores $<9^{\text {th }}$ percentile) (Wilkinson 1993), overt neurological disease, endocrine disease, depressive disorders, conduct disorder or psychotic symptoms, to remove confounding factors for the dependent variables under examination. There was no refusal to participate. The clinical research protocol was Hospital Ethics Committee approved. All participants and their caregivers were given verbal and written information and written informed consent was obtained from each participant's 
caregiver before entering the study. Chi-square tests revealed that the ADHD groups were balanced for oppositional defiant disorder [ADHD-CT alone: 63\%; ADHD-CT and anxiety: $65 \%]$. The distributions of anxiety disorders in the anxiety groups were the same [ADHD-CT and anxiety: GAD-54\%; SAD-26\%; SoPh-35\%; SpPh-50\%; anxiety disorders alone: GAD-60\%; SAD-26\%; SoPh-30\%; SpPh-50\%]. None of the anxiety alone group had comorbid oppositional defiant disorder.

\section{Insert Table 1 here}

Measures

The K-SADS-PL (Kaufman et al. 2000) is a structured diagnostic interview schedule based on DSM-IV criteria $(0=$ no information, $3=$ threshold $)$, with a parent version. It has proven clinical utility, reliability (inter-rater reliability kappa $>0.75$ $[\mathrm{kappa}=0.89$ current sample $])$ and validity.

Conners' Global Index (CGI) (Conners et al. 1997) is a 10-item questionnaire that outlines the core symptom domains of ADHD-CT (clinical cut-off $>/=15,0=$ not at all, $3=$ very much). It is completed by parent(s) and teachers and yields a continuous variable of ADHD-CT symptoms. It has good validity and reliability (inter-rater reliability kappa $>0.80[\mathrm{kappa}=.84$ current sample]; Cronbach's alpha $>0.80$ [alpha $=$ 0.90 current sample]).

The Achenbach Child Behaviour Checklist (CBCL) (Achenbach 1991) consists of 112 behaviour problem items which are rated by a parent on a 3-point scale as to how applicable each is to the child $(0=$ not true, $2=$ very/often true $)$. The attention and anxiety/depression subscales are ascertained. The CBCL is well researched, has adequate psychometric properties (inter-rater reliability kappa $>0.80[\mathrm{kappa}=.92 / .90$ 
attention and anxiety/depression subscales current sample]; Cronbach's alpha > $0.80[$ alpha $=0.94 / 0.91$ attention and anxiety/depression subscales current sample]).

The Revised Children's Manifest Anxiety Scale (R-CMAS) (Reynolds and Richmond 1985) consists of 37 items designed to assess child self-report of anxiety $(0=$ no, $1=$ yes $)$. The total anxiety $\mathrm{T}$ score is ascertained. The children in this study completed the questionnaire on their own. Good test-retest reliability, consistency (Cronbach's alpha $>0.80$ [alpha $=0.84$ current sample]) and concurrent validity have been demonstrated.

The third edition of the Wechsler Intelligence Scale for Children (WISC-III) (Wechsler 1991) was used. This provides verbal, performance, and full-scale scores of measured intelligence. The WISC-III is well established with good test-retest reliability and consistency (Cronbach's alpha $>0.80$ [alpha $=0.89$ current sample $]$ ).

The Wide Range Achievement Test, third edition (WRAT-3) (Wilkinson 1993) is an academic achievement screening test that assesses reading, arithmetic and spelling. Disorders are probable if the percentile rank is $<9^{\text {th }}$ percentile. Internal consistency for this test is moderate to high $(\mathrm{r}=.69-.95)$. Concurrent validity is also fair to high as correlations between the WRAT-3 and other achievement tests range from .41-.87.

Spatial working memory, including Between Search Errors and Strategy, and Spatial Span were assessed using the Cambridge Neuropsychological Test Automated Battery [CANTAB] (Robbins et al. 1994). During recent years, the CANTAB has been used to evaluate non-verbal tests of memory, attention, and executive function in different neuro-psychiatric conditions, including ADHD (Gau and Shang, 2010; Kempton et al. 1999; Levaux et al. 2007; Rhodes et al. 2005). The CANTAB consists of a series of computerized non-verbal tests of memory, attention, and executive function 
(working memory and planning). The tests are administered using a computer with a touch sensitive screen and reaction time is ascertained. The spatial working memory task is a self-ordered searching task that requires the participant to use mnemonic information to work towards a goal: Between search errors (BSE) are 'forgetting' errors committed when a box previously opened and emptied of a blue token is re-visited during a search with $3,4,6$ or 8 boxes (range 0-no upper limit). The Strategy score is estimated from the participant's performance on the six and eight box levels (range 0-no upper limit). It reflects the number of times a searching sequence is initiated from the same box during a trial. A high strategy scores represents low use of this strategy and lower scores represent more consistent use of this strategy. The Spatial Span task is a computerised version of the Corsi Block Tapping Test that assesses the participant's ability to remember a sequence of squares presented on the screen. The span score is calculated as the highest level at which the participant successfully remembers at least one sequence of boxes (range 0-9). A large positive correlation (Pearson's r=.60) between the BSE (forgetting) variable and the strategy (organizing) variable, and a medium negative correlation (Pearson's $\mathrm{r}=-.50$ ) between the BSE and the span (capacitance) variable have been shown for children and adolescents with ADHD (Barnett, 2001). The relationship between spatial working memory and prefrontal cortical-linked neural networks is constrained by single neuronal firing rates in alert primates (Goldman-Rakic 1987; 1995), studies of behaviour in alert primates completing these tasks (Nagahara et al. 2010; Sahakian and Owen 1992) and following focal PFC lesions in adult humans (Owen et al. 1993) and studies of patterns of regional cerebral blood flow in healthy humans performing these SWM tests (D'Esposito et al. 1995). Further, these spatial working memory experimental paradigms can be applied unchanged to the study of executive function in young children where limited linguistic 
skills often preclude the assessment of other executive processes. For example, children as young as 4 years can perform the two tasks, although test performance correlates positively with age (Luciana and Nelson, 1998). More detailed descriptions and illustrations of the CANTAB tests can be found in Fray et al. (1996) and at the CANTAB website (http://www.cantab.com/cantab-for-academic-research.asp).

Procedure

Testing occurred over two sessions with breaks as needed. Each parent and their child was assessed in separate rooms by different trained clinical researchers. During the first session, the parent was interviewed using the K-SADS-PL while his/her child completed the R-CMAS, the WISC-III and the WRAT-3. During the second session, the child completed the CANTAB spatial working memory and spatial span tasks while their parent completed the Conners' and CBCL questionnaires.

Statistical Analysis

Data analysis was performed using the Statistical Package for the Social Sciences (SPSS/SC). All dimensional variables were normally distributed. Performance on the (1) SWM BSE variable, including both the accuracy and response latency variables, and (2) the Strategy and Spatial Span variables was compared between groups using respective (1) repeated-measures and (2) one-way analysis of covariance (ANCOVA). Partial eta-squared statistics are provided for significant main effects between groups. A small, medium and large effect is indicated by $.01, .06$ and .14 , respectively (Cohen, 1988). To investigate the contribution of Spatial Span and Strategy to overall SWM, the correlations between BSE and Spatial Span and between BSE and Strategy were computed using the total number of BSE's (across all levels of difficulty), for each of the clinical and healthy control groups. To investigate the 
association of SWM with anxiety and ADHD-CT symptoms, the correlation between the total number of BSE's, Spatial Span and Strategy, and anxiety and ADHD-CT symptoms, separately, were computed in the combined sample, including healthy control and clinical participants. In all analyses, the effects of age and performance IQ were controlled, given the known sensitivity of these SWM measures to these variables (Barnett et al. 2005; Kravariti et al. 2003).

\section{Results}

In the spatial working memory task, there was a significant effect of condition (increasing number of boxes), Wilks' $\lambda=0.75, F(3,584)=58.48, p<0.0005]$, and group, $F(3,586)=7.58, p=<0.0005$, partial $\eta^{2}=0.04$, with the ADHD with and without anxiety groups and the anxiety disorders alone group being associated with increased between search errors (BSE), after controlling for performance IQ, $F(1,586)$ $=41.51, p<0.0005$, partial $\eta^{2}=0.07$, which had a significant independent association with BSE (see Table 2 and Figure 1). Also, there was a significant interaction between BSE and group, Wilks' $\lambda=0.95, F(9,1421)=3.22, p=0.001$, after controlling for performance IQ, Wilks' $\lambda=0.93, F(3,584)=13.32, p<0.0005$, again which had a significant independent association with BSE. This interaction suggested that the above group differences were more apparent as task difficulty increased (Figure 1). Further, the two ADHD groups had significantly more BSE than the anxiety disorders alone group which had significantly more BSE than the healthy control participants. Interestingly, these relationships were age-independent: the significant interaction between BSE and group, Wilks' $\lambda=0.89, F(9,1421)=7.43, p<0.0005$, remained after accounting for age, Wilks' $\lambda=0.81, F(3,584)=44.60, p<0.0005$, which had a significant independent association with BSE. Importantly, the groups did not differ in the time taken to complete each difficulty level of the task (Table 2). 


\section{Insert Table 2 here}

Spatial Span, $F(3,586)=10.96, p=<0.0005$, partial $\eta^{2}=0.06$, differed between the groups, after controlling for performance IQ, $F(1,586)=39.25, p=<0.0005$, partial $\eta^{2}=0.07$, which had a significant independent association with spatial span. The two ADHD groups had a worse spatial span than both the anxiety disorders alone group and the healthy control group. Further, the anxiety disorders alone group had a worse spatial span than the healthy control group. Similarly, Strategy, $F(3,586)=3.64, p=$ 0.01 , partial $\eta^{2}=0.02$, differed between the groups, after controlling for performance IQ, $F(1,586)=44.15, p=<0.0005$, partial $\eta^{2}=0.08$, again which had a significant independent association with strategy. The two ADHD groups had a worse strategy performance than the anxiety disorders alone and healthy control group, while the anxiety disorders alone group did not differ from the healthy control group.

\section{Insert Figure 1 here}

The pattern of intercorrelations between BSE, Spatial Span and Strategy was qualitatively similar for the healthy control, BSE: Spatial Span $r=-0.33, p<0.0005$; BSE: Strategy $r=0.68, p<0.0005$, anxiety disorders alone, BSE: Spatial Span $r=-$ $0.34, p<0.0005$; BSE: Strategy $\mathrm{r}=0.57, p<0.0005$, ADHD and anxiety, BSE: Spatial Span $\mathrm{r}=-0.34, p<0.0005$; BSE: Strategy $\mathrm{r}=0.31, p<0.0005$, and ADHD alone, BSE: Spatial Span $\mathrm{r}=-0.31, p<0.0005$; BSE: Strategy $\mathrm{r}=0.31, p<0.0005$, groups, after controlling for age and performance IQ. For all groups there was a medium strength correlation between Spatial Span and BSE and a medium to large strength correlation between Strategy and BSE. 
Parent and child reported anxiety symptoms had a small strength positive correlation with BSE, $\mathrm{r}=.22 / .19, p=.008 / .01$, respectively, small strength negative correlation with Spatial Span, r=-.24/-.17, $p=.006 / .02$, respectively, and a nonsignificant correlation with Strategy. In contrast, parent reported ADHD symptoms in their children had a small strength positive correlation with BSE and Strategy, $\mathrm{r}=.31 / .28, p=.008 / .006$, respectively, and small strength negative correlation with Spatial Span, $\mathrm{r}=-.26, p=.004$. All these correlations were calculated after controlling for age and performance IQ.

\section{Discussion}

In this study, between search errors (BSE) were examined as the key dependent measure of the SWM task (Gau and Shang 2010; Kempton et al. 1999). The ADHD groups manifest impairment whether anxiety was present or not compared to the anxiety disorders alone group, which, in turn, was impaired compared to the healthy control group. In all groups, performance differences increased as task difficulty (SWM load) increased. Further, these findings were age independent: SWM improved in all groups as age increased although the relative differences between the groups did not change. This suggests that these relative differences were not moderated by developmental maturation effects that improve SWM. Hence, these data do not suggest an additive effect of ADHD and anxiety on SWM deficits but do support anxiety disorders alone being associated with impaired SWM performance compared to healthy control participants. The spatial span component findings were consistent with these two interpretations. Similarly, the strategy component results confirmed a non-additive effect of ADHD and anxiety. Interestingly, however, the anxiety disorders alone group did not differ from healthy control participants in their strategy ability suggesting that in this group the deficits in SWM related to spatial span impairment alone. Importantly, 
the lack of an additive effect of ADHD and anxiety was not due to ceiling effects for BSE and strategy scores or a floor effect for the spatial span score.

The groups did not manifest differences in their motor execution to perform the SWM and spatial span tasks and their approach to completing them. This was evinced by the clinical and healthy control groups having qualitatively similar intercorrelations of BSE, spatial span and strategy components, similar reaction times for the SWM tests and the participants' anxiety symptoms being correlated with BSE positively and spatial span negatively, but not with strategy. In contrast, participants' ADHD symptoms correlated with BSE, spatial span and strategy components.

The clinical and healthy control groups used in this study were carefully defined categorically and dimensionally (see Table 1). Consistent with the published literature, the three clinical groups had lower verbal, non-verbal and fullscale IQ compared to the healthy control participants with the ADHD +/- anxiety groups performing worse than the anxiety disorders alone group (Biederman et al. 2009). These differences in IQ were controlled in the analyses conducted to preserve the essential characteristics of the ADHD +/- anxiety and anxiety disorders alone groups rather than matching the groups for verbal and non-verbal IQ and potentially skewing these characteristics (Dennis, Francis, Cirino, Schachar, \& Barnes, 2009).

These findings replicate and extend the previous findings of Manassis et al. (2007): there was no additive effect of ADHD and anxiety on SWM performance. But anxiety disorders alone were associated with impaired SWM performance that appeared related to spatial span impairment alone. The results also support the model these authors proposed of working memory dysfunction underpinning ADHD and anxiety, together and separately. The findings are also consistent with the known impairing 
effects of anxiety, defined as anxious arousal, on SWM performance (Koric et al. 2011; Lavric et al. 2003; Shackman et al. 2006). In contrast, anxiety defined as worry (anxious apprehension), seems to primarily affect verbal WM in recent influential models (Eysenck, Devakshan, Santos, \& Calvo, 2007; Humphreys and Revelle 1984): in essence, these models suggest that increasing anxiety diminishes access to storage and processing resources of the predominantly verbal WM system while augmenting motivational functions leading to enhanced effort and strategy. Thus strategy and reaction time functions may be relatively preserved while 'on-line' working memory maintenance functions may be impaired. A recent study of better sustained and selective attention in children and adolescents with ADHD and anxiety demonstrated this enhanced motivational functioning (Vloet, Konrad, Herpetz-Dahlmann, Polier, \& Gunther, 2010). Interestingly, our findings in anxiety disorders alone are congruent with these influential models, albeit in the SWM rather than verbal WM domain. Nevertheless, SWM and verbal WM are also clearly interrelated and are, in part subserved by similar neural networks (Karatekin 2004; McNab et al. 2008). Future studies should also examine verbal WM along with SWM to explore this interrelationship more thoroughly. Importantly, these impairing effects of anxiety on SWM performance are not additionally evident in the setting of ADHD, suggesting that these participants are already evincing maximal impairment in SWM performance as a consequence of their ADHD status.

Importantly, cognitive neuroscience studies suggest that there are two functionally distinct subdivisions of the lateral frontal cortex that subserve different components of SWM (Owen et al. 1996; Smith et al. 1996): During the 'online' maintenance of spatial information in working memory, assessed using a task identical to the CANTAB measure of 'spatial span', there was significant activation in the 
ventrolateral prefrontal cortex (Brodmann Area 47), while the active monitoring and manipulation of spatial information within working memory (strategy) was associated with significant activation in mid-dorsolateral prefrontal cortical areas 9 and 46. Further, it is known that dysfunction in fronto-striatal-parietal neural networks is associated with impaired abilities in the maintenance and manipulation of spatial information in SWM (Braver et al. 1997; 2001; Owen et al. 1995; Vance et al. 2007). Given the constrained brain -behaviour relationships of the SWM and spatial span tasks used in this study, we can proffer the following tentative cognitive neuroscience assertions, based on the data outlined, although tempered by the lack of brain activation data: the ADHD groups may have dysfunction of frontal-striatal-parietal neural networks involving both the ventrolateral prefrontal and the mid-dorsolateral prefrontal cortices. In contrast, the anxiety disorders alone group may have dysfunction of frontalstriatal-parietal neural networks involving primarily the ventrolateral prefrontal cortex with relative sparing of mid-dorsolateral prefrontal cortical function.

There are a number of implications for clinical practice and research future directions that arise from these results. First, children and adolescents need to be comprehensively assessed for impairing patterns of anxiety symptoms from multiple informants: child self-report and parent report as a minimum to ensure their early recognition. Second, young people with ADHD combined type, whether anxiety is present or not, may have a considerably worsening performance on tasks in situations that make increasing cognitive demands on them. This needs to be optimally treated with stimulant or non-stimulant medications to facilitate and optimise emerging working memory training cognitive behavioural therapy (CBT) techniques to aid working memory and its span and strategy components (Gathercole and Alloway, 2006; Holmes, Gathercole, \& Dunning, 2009). Indeed, a future step will be developing span- 
and strategy-specific CBT approaches. Anxiety reduction CBT interventions can be used to manage the impairing comorbid anxiety symptoms (Vance, 2011). The management of anxiety disorders needs to incorporate a focus on the cognitive domain: Anxiety disorders can be effectively treated with anxiety reduction CBT techniques along with working memory training to aid working memory and especially its span component. A clear future research aim should be possible stimulant and/or nonstimulant medication randomised control trials to evaluate their effectiveness for ameliorating working memory and particularly its span component in anxiety disorders. In school settings, information may need to be presented simply and instructions conveyed in small amounts to optimise understanding and learning, given the recognised link between impaired working memory performance and decreased educational achievement (Gathercole and Alloway 2006; Rapport et al. 1999).

Future research should also explore whether the finding of SWM deficits related to spatial span alone may help differentiate anxiety disorders alone from ADHD and anxiety, given the latter's association with impaired strategy performance as well. This could potentially be a clinically useful way of separating these two groups of children and adolescents with inattentive problems. Future systematic cross sectional and longitudinal studies are needed. In addition, the association of anxiety with ADHD inattentive type needs to be systematically examined. Also the association of ADHD with other types of anxiety and early onset depressive disorders need to be studied to comprehensively survey this deeply linked vulnerability with ADHD (Zavos, Rijsdiijk, Gregory, \& Eley, 2010).

A key limitation of this study is the narrow focus on SWM without further examination of the intimately related attentional system and memory encoding and retrieval systems. However, the number of additional cognitive tasks needed ensures 
that these systems will be the focus of future clinical research studies in the patient populations noted above. In addition, these results are cross sectional and therefore do not address longitudinal processes of change. Further, there was no assessment of brain activation in this study to further elucidate brain behaviour relationships in these clinical and typically developing participant groups. The sample examined was also limited in its generalisability because of the medication naïve status of the clinical cases and the lack of common comorbid conditions, for example learning disorders.

In summary, this study found no evidence of an additive effect of ADHD and anxiety on SWM, strategy and spatial span deficits in a large sample of carefully defined children and adolescents. But, anxiety disorders alone were associated with impaired SWM and span performance compared to healthy control participants. In contrast, strategy did not differ between children and adolescents with anxiety disorders alone and healthy control participants, suggesting that the deficits in SWM related to spatial span impairment alone. These data concur with current influential theories about the cognitive effects of anxiety on performance. They also imply that anxiety may be subserved by dysfunction of frontal-striatal-parietal neural networks involving primarily the ventrolateral prefrontal cortex with relative sparing of mid-dorsolateral prefrontal cortical function: ADHD clearly is subserved by dysfunction in all these brain regions. Future clinical research should systematically investigate all the aspects of the anxietydepression vulnerability and extend the verbal and spatial working memory paradigms to the closely related attention and memory encoding and retrievaltasks. 


\section{References}

Achenbach, T.M. (1991). Manual for the Child Behavior Checklist / 4-18 and 1991 Profile. Burlington, V.T.: University of Vermont, Department of Psychiatry.

American Psychiatric Association. (2000). Diagnostic and Statistical Manual of Mental Disorders. (4 ${ }^{\text {th }}$ ed., Text Revision). Washington, DC: American Psychiatric Association.

Aronen, E.T., Vuontela, V., Steenari, M.R., Salmi, J., \& Carlson, S. (2005). Working memory, psychiatric symptoms and performance at school. Neurobiology of Learning and Memory, 83, 33-42.

Awh, E., \& Jonides, J. (2001). Overlapping mechanisms of attention and spatial working memory. Trends in Cognitive Science, 5, 119-126.

Baddeley, A.D. (1986). Working Memory. Oxford: Clarendon Press.

Barnett, R., Maruff, P., \& Vance, A. (2005). An investigation of visuospatial memory impairment in children with attention deficit hyperactivity disorder (ADHD), combined type. Psychological Medicine, 35, 1433-1443.

Barnett, R., Vance, A.L.A., Maruff, P., Luk, S.L., Costin, J., \& Pantelis, C. (2001). Abnormal executive function in attention deficit hyperactivity disorder: The effect of stimulant medication and age on spatial working memory. Psychological Medicine, 31, 1107-1115.

Bedard, A.C., \& Tannock, R. (2008). Anxiety, methylphenidate response and working memory in children with ADHD. Journal of Attention Disorders, 11, 546-557.

Biederman, J., Faraone, S.V., \& Mick, E. (1999). Clinical correlates of ADHD in females: findings from a large group of girls ascertained from pediatric and psychiatric referral sources. Journal of the American Academy of Child and Adolescent Psychiatry, 38, 966-975. 
Biederman, J., Petty, C.R., Ball, S.D.W., Fried, R., Doyle, A.E., \& Cohen, D. (2009). Are cognitive deficit in ADHD related to course of disorder? A prospective study of boys with a remitting and persistent course. Psychiatry Research, 170, 177-182.

Braver, T.S., Barch, D.M., Kelley, W.M., Buckner, R.L., Cohen, N.J., \& Miezen, F.M. (2001). Direct comparison of prefrontal cortex regions engaged by working and long-term memory tasks. NeuroImage, 14, 48-59.

Braver, T.S., Cohen, J.D., Nystrom, L.E., Jonides, J., Smith, E.E., \& Noll, D.C. (1997). A parametric study of prefrontal cortex involvement in human working memory. NeuroImage, 5, 49-62.

Cantwell, D.P., \& Barker, L. (1992). Attention deficit disorder with and without hyperactivity: a review and comparison of matched groups. Journal of the American Academy of Child and Adolescent Psychiatry, 31, 432-438.

Castellanos, F.X., \& Tannock, R. (2002). Neuroscience of attention-deficit/hyperactivity disorder: the search for endophenotypes. Nature Reviews Neuroscience, 3, 617-28.

Cohen, J. (1988). Statistical power analysis for the behavioral sciences (2nd ed.). Mahwah, NJ:

Lawrence Erlbaum.

Conners, C.K., Wells, K.C., Parker, J.D., Sitarenios, G., Diamond, J.M., \& Powell, J.W. (1997). A new self-report scale for assessment of adolescent psychopathology: factor structure, reliability, validity, and diagnostic sensitivity. Journal of Abnormal Child Psychology, 25, 487-497.

D’Esposito, M., Detre, J.A., Alsop, D.C., Shin, R.K., Atlas, S., \& Grossman, M. (1995). The neural basis of the central executive system of working memory. Nature, 378, 279-281. 
Dennis, M., Francis, D.J., Cirino, P.T., Schachar, R., Barnes, M.A., \& Fletcher, J.M. (2009). Why IQ is not a covariate in cognitive studies of neurodevelopmental disorders. Journal International Neuropsychological Society, 15, 331-343.

Eysenck, M.W., \& Devakshan, N., Santos, R., \& Calvo, M.G. (2007). Anxiety and cognitive performance: attentional control theory. Emotion, 7, 336-353.

Fray, P.J., Robbins, T.W., \& Sahakian, B.J. (1996). Neuropsychiatric applications of CANTAB. International Journal of Geriatric Psychiatry, 11, 329-336.

Gathercole, S.E., \& Alloway, T.P. (2006). Practitioner review: short-term and working memory impairments in neurodevelopmental disorders: diagnosis and remedial support. Journal of Child Psychology and Psychiatry, 47, 4-15.

Gau, S.S., \& Shang, C.Y. (2010). Executive functions as endophenotypes in ADHD: evidence from the Cambridge Neuropsychological Test Battery (CANTAB). Journal of Child Psychology and Psychiatry, 51, 838-49.

Goldman-Rakic, P.S. (1987). Circuitry of the primate prefrontal cortex and regulation of behaviour by representational memory. In F.Plum (Ed.), Handbook of Physiology, The Nervous System, Higher functions of the Brain Vol. V (pp. 373-417). Maryland: American Physiological Society

Goldman-Rakic, P.S. (1995). Architecture of the prefrontal cortex and the central executive. In J. Grafman, K. J. Holoyoak \& F. Boller (Eds.), The Structure and function of the Prefrontal Cortex, Vol. 769. Annals of the New York Academy of Sciences (pp. 7183). New York: New York Academy of Sciences.

Holmes, J., Gathercole, S.E., \& Dunning, D.L. (2009). Adaptive training leads to sustained enhancement of poor working memory in children. Developmental Science, 12, F915. 
Humphreys, M.S., \& Revelle, W. (1984). Personality, motivation and performance: a theory of the relationship between individual differences and information processing. Psychological Review, 91, 153-184.

Ikeda, M., Iwanaga, M., \& Seiwa, H. (1996). Test anxiety and the working memory system. Perceptual and Motor Skills, 82, 1223-1231.

Jensen, P.S., Hinshaw, S.P., \& Kraemer HC. (2001). ADHD comorbidity findings from the MTA: comparing comorbid subgroups. Journal of the American Academy of Child and Adolescent Psychiatry, 40, 147-158.

Jensen, P.S., Martin, D., \& Cantwell, D.P. (1997). Comorbidity of ADHD: implications for research, practice and DSM-V. Journal of the American Academy of Child and Adolescent Psychiatry, 36, 1065-1079

Karatekin, C. (2004). A test of the integrity of the components of Baddeley's model of working memory in attention-deficit/hyperactivity disorder (ADHD). Journal of Child Psychology and Psychiatry, 45, 912-926.

Kaufman, J., Birmaher, B., Brent, D.A., Ryan, N.D., \& Rao, U. (2000). Schedule for Affective Disorders and Schizophrenia for School-Age Children - Present and Lifetime Version (K-SADS-PL). The K-SADS-PL. Journal of the American Academy of Child and Adolescent Psychiatry, 39, 49-58.

Kempton, S., Vance, A., Maruff, P., Luk, E., Costin, J., \& Pantelis, C. (1999). Executive function and attention deficit hyperactivity disorder: stimulant medication and better executive function performance in children. Psychological Medicine, 29, 527-38.

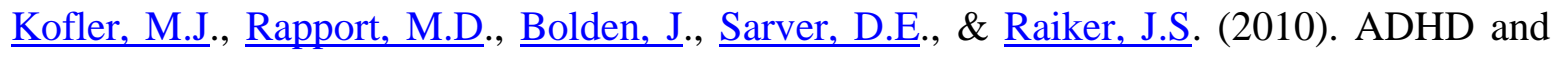
working memory: the impact of central executive deficits and exceeding storage/rehearsal capacity on observed inattentive behavior. Journal of Abnormal Child Psychology 38, 149-61. 
Koric, L., Volle, E., Seassau, M., Bernard, .FA,, Mancini, J., \& Dubois, B. (2011) How cognitive performance-induced stess can influence right VLPFC activation: an fMRI study with healthy subjects and patients with social phobia. Human Brain Mapping (in press).

Kravariti, E., Morris, R., Rabe-Hesketh, S., Murray, R.M., \& Frangou, S. (2003). The Maudsley early-onset schizophrenia study: Cognitive function in adolescent-onset schizophrenia. Schizophrenia Research, 65, 95-103.

Ladouceur, C.D., Dahl, R.E., Williamson, D.E., Birmaher, B., Ryan, N.D., \& Casey, B.J. (2005). Altered emotional processing in pediatric anxiety, depression and comorbid anxiety-depression. Journal of Abnormal Child Psychology, 33, 165-177.

Last, C.G., Hersen, M., Kazdin, A., Orvaschel, H, \& Perrin, S. (1991). Anxiety Disorders in children and their families. Archives of General Psychiatry, 48, 928-934.

Lavric, A., Rippon, G., \& Gray, J.R. (2010). Threat-evoked anxiety disrupts spatial working memory performance: an attentional account. Cognitive Therapy and Research, 27, 489-504.

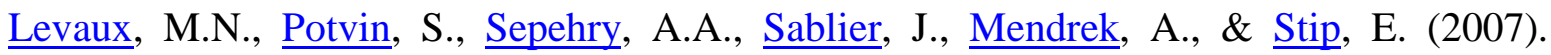
Computerized assessment of cognition in schizophrenia: Promises and pitfalls of CANTAB. European Psychiatry, 22, 104-115.

Li, X., \& Chan, R.C.K., \& Luo, Y-J. (2010). Stage effects of negative emotion on spatial and verbal working memory. BMC Neuroscience, 11, 60.

Luciana, M., \& Nelson, C.A. (1998). The functional emergence of prefrontally-guided working memory systems in four- to eight-year-old children. Neuropsychologia, 36, 273-93. 
Manassis, K., Tannock, R., Young, A., \& Francis-John, S. (2007). Cognition in anxious children with ADHD: a comparison of clinical and normal children. Behavioral and Brain Functions, 15, 3-4.

March, J.S., Swanson, J.M., Arnold, L.E., Hoza, B., Conners, C.K., \& Hinshaw, S.P. (2000). Anxiety as a Predictor and Outcome Variable in the Multimodal Treatment Study of Children with ADHD (MTA). Journal of Abnormal Child Psychology, 28, $527-541$.

Martinussen, R., Hayden, J., Hogg-Johnson, S., \& Tannock, R. (2005). A meta-analysis of working memory impairments in children with ADHD. Journal of the American Academy of Child and Adolescent Psychiatry, 44, 377-384.

McNab, F., Leroux, G., Strand, F., Thorell, L., Bergman, S., \& Klingberg, T. (2008).

Common and unique components of inhibition and working memory: an fMRI, within-subjects investigation. Neuropsychologia, 46, 2668-2682.

Merikangas, K.R., He, J.P., Burstein, M., Swendsen, J., Avenevoli, S., \& Case, B. (2011). Service utilization for lifetime mental disorders in US adolescents: results of the National Comorbidity Study - Adolescent Supplement (NCS-A). Journal of the American Academy of Child and Adolescent Psychiatry, 50, 32-45.

Nagahara, A.H., Bernot, T., \& Tuszynski, M.H. (2010). Age-related cognitive deficits in rhesus monkeys mirror human deficits on an automated test battery. Neurobiology Aging, 31, 1020-1031.

Nigg, J.T. (2000). On inhibition/disinhibition in developmental psychopathology: views from cognitive and personality psychology and a working inhibition taxonomy. Psychological Bulletin, 126, 240-266. 
Owen, A.M., Evans, A.C., \& Petrides, M. (1996). Evidence for a two-stage model of spatial working memory processing within the lateral frontal cortex: A positron emission tomography study. Cerebral Cortex, 6, 31-38.

Owen, A.M,, Roberts, A.C., Hodges, J.R., Summers, B.A., Polkey, C.E., \& Robbins, T.W. (1993). Contrasting mechanisms of attentional set-shiftng in patients with frontal lobe damage or Parkinson's Disease. Brain, 116, 1159-1175.

Owen, A.M., Sahakian, B.J., Semple, J., Polkey, C.E., \& Robbins, T.W. (1995). Visuospatial short-term recognition memory and learning after temporal lobe exicisions, frontal lobe excisions or amygdalo-hippocampectomy in man. Neuropsychologia, $33,1-24$.

Polanczyk, G., de Lima, M.S., Horta, B.L., Biederman, J., \& Rohde, LA. (2007). The worldwide prevalence of ADHD: a systematic review and metaregression analysis. American Journal of Psychiatry, 164, 942-948.

Postle, B.R. (2006). Distraction-spanning sustained activity during delayed recognition of locations. Neuroimage, 30, 950-962.

Rapport, M.D., Scanlan, S.W., \& Denney, C.B, (1999). ADHD and scholastic achievement: a model of dual developmental pathways. Journal of Child Psychology and Psychiatry, 40, 1169-1183.

Reynolds, C.R. \& Richmond, B.O. (1985). Revised Children's Manifest Anxiety Scale. Los Angeles, CA: Western Psychological Services.

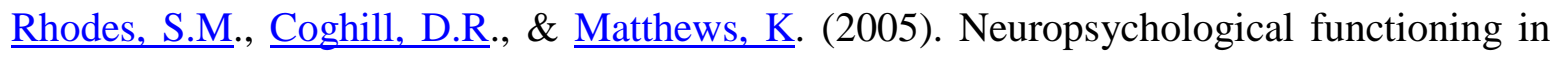
stimulant-naive boys with hyperkinetic disorder. Psychological Medicine, 35, 110920.

Robbins, T.W., James, M., Owen, A.M., Sahakian, B.J., McInnes, L., \& Rabbitt, P. (1994). Cambridge Neuropsychological Test Automated Battery (CANTAB): a factor 
analytic study of a large sample of normal elderly volunteers. Dementia, 5, 26681.

Sahakian, B.J., \& Owen, A.M. (1992). Computerised assessment in neuropsychiatry using CANTAB: discussion paper. Journal of the Royal Society of Medicine, 85, 399402.

Schatz, D.B., \& Rostain, A.L. (2006). ADHD with comorbid anxiety: a review of the literature. Journal of Attention Disorders, 10, 141-149.

Shackman, A.J, Sarinopoulos, I., Maxwell, J.S., Pizzagalli, D.A., Lavric, A., \& Davidson R.J. (2006). Anxiety selectively disrupts visuospatial working memory. Emotion, $6,40-61$.

Smith, E.E., Jonides, J., \& Koeppe, R.A. (1996). Dissociating verbal and spatial working memory using PET. Cerebral Cortex, 6, 11-20.

Staugaard, S.R. (2010). Threatening faces and social anxiety: a literature review. Clinical Psychology Review, 30, 669-690.

Tannock, R. (2009). ADHD with anxiety disorders. In ADHD comorbidities: Handbook for ADHD complications in children and adults (ed. T.E. Brown), pp. 131-156. Washington DC: American Psychiatric Association Press,

Tannock, R., Ickowicz, A., \& Shachar, R. (1995). Differential effects of methylphenidate on working memory in ADHD children with and without comorbid anxiety. Journal of the American Academy of Child and Adolescent Psychiatry, 34, 886-896.

Vance, A., Barnett, R., Costin, J., Luk, S.L., Maruff, P., \& Tonge, B.J. (2002). Characteristics of parent- and child-reported anxiety in psychostimulant medication naïve, clinically referred children with attention deficit hyperactivity disorder, combined type (ADHD-CT). Australian and New Zealand Journal of Psychiatry, $36,234-239$. 
Vance, A., Silk, T., Casey, M., Rinehart, N., Bradshaw, J., \& Bellgrove, M. (2007). Right parietal dysfunction in children with Attention Deficit Hyperactivity Disorder, combined type: a functional MRI study. Molecular Psychiatry, 12, 826-832.

Vance, A. (2011). Differential diagnosis and comorbid ADHD in childhood anxiety. In Handbook of Child and Adolescent Anxiety Disorders (ed. E. Storch, D. McKay), pp. 121-134. New York: Springer,

Vloet, T.D., Konrad, K., Herpetz-Dahlmann, B., Polier, G.G., \& Gunther, T. (2010). Impact of anxiety on attentional functions in children with ADHD. Journal Affective Disorders, 124, 283-290.

Wechsler, D. (1991). Wechsler Intelligence Scale for Children (3rd ed.). Texas: The Psychological Corporation.

Wilkinson, G.S. (1993). Wide Range Achievement Test 3 (WRAT-3). Delaware: Wilmington.

Willcutt, E.G., Doyle, A.E., Nigg, J.T., Faraone, S.V,, \& Pennington, B.F. (2005). Validity of the executive function theory of attention-deficit/hyperactivity disorder: a metaanalytic review. Biological Psychiatry, 57, 1336-1346.

Wolraich, M.L., Hannah, J.N., Pinnock, T.Y., Baumgaertel, A., \& Brown, J. (1996). Comparison of diagnostic criteria for ADHD in a county-wide sample. Journal of the American Academy of Child and Adolescent Psychiatry, 35, 319-324.

Woolston, J.L., Rosenthal, S.L., Riddle, M.A., Sparrow, S.S., Cicchetti, D, \& Zimmerman, L.D. (1989). Childhood comorbidity of anxiety/affective disorders and behaviour disorders. Journal of the American Academy of Child and Adolescent Psychiatry, $28,707-713$. 
Zavos, H.M., Rijsdiijk, F.V., Gregory, A.M., \& Eley TC. (2010). Genetic influences on cognitive biases associated with anxiety and depressive symptoms in adolescents. Journal of Affective Disorders, 124, 45-53. 


\section{TABLE 1}

Participant characteristics of ADHD alone, ADHD and anxiety (ADHDANX), anxiety alone (ANX) and healthy control groups

\begin{tabular}{|c|c|c|c|c|c|c|}
\hline & $\begin{array}{c}1 \\
\text { ADHD } \\
N=163\end{array}$ & $\begin{array}{c}2 \\
\text { ADHDANX } \\
N=\mathbf{2 4 3}\end{array}$ & $\begin{array}{c}3 \\
\text { ANX } \\
N=69\end{array}$ & $\begin{array}{c}4 \\
\text { Controls } \\
N=116\end{array}$ & $F$ & $\begin{array}{c}\text { Group } \\
\text { differences }\end{array}$ \\
\hline $\begin{array}{l}\text { Age } \\
\text { (months) }\end{array}$ & $\begin{array}{l}139.82 \\
(31.11)\end{array}$ & $\begin{array}{l}134.57 \\
(28.77)\end{array}$ & $\begin{array}{l}140.61 \\
(27.24)\end{array}$ & $\begin{array}{l}135.97 \\
(26.31)\end{array}$ & 1.51 & $\mathrm{NS}$ \\
\hline $\begin{array}{l}\text { Gender } \\
(\mathbf{M}, \mathbf{F})\end{array}$ & 141,22 & 187,56 & 52,17 & 94,22 & $1.34^{b}$ & $\mathrm{NS}$ \\
\hline CGI & $\begin{array}{l}17.77^{*} \\
(6.69)\end{array}$ & $\begin{array}{l}19.57 * \\
(6.43)\end{array}$ & $\begin{array}{l}9.83 \\
(6.67)\end{array}$ & $\begin{array}{l}3.13 \\
(3.64)\end{array}$ & 194.13 & $1=2>3>4 \# \#$ \\
\hline $\begin{array}{l}\text { CBCL } \\
\text { att }\end{array}$ & $\begin{array}{l}70.79^{*} \\
(9.06)\end{array}$ & $\begin{array}{l}72.25^{*} \\
(10.78)\end{array}$ & $\begin{array}{l}58.59 \\
(6.78)\end{array}$ & $\begin{array}{l}52.49 \\
(4.30)\end{array}$ & 156.20 & $1=2>3>4 \# \#$ \\
\hline $\begin{array}{l}\text { CBCL } \\
\text { anxdep }\end{array}$ & $\begin{array}{l}61.06 \\
(8.88)\end{array}$ & $\begin{array}{l}67.03^{*} \\
(10.98)\end{array}$ & $\begin{array}{l}66.93 * \\
(10.56)\end{array}$ & $\begin{array}{l}53.77 \\
(5.88)\end{array}$ & 55.31 & $2=3>1>4 \# \#$ \\
\hline $\begin{array}{l}\text { RCMAS } \\
\text { total }\end{array}$ & $\begin{array}{l}50.14 * \\
(11.86)\end{array}$ & $\begin{array}{l}53.08^{*} \\
(11.99)\end{array}$ & $\begin{array}{l}52.15^{*} \\
(12.05)\end{array}$ & $\begin{array}{l}39.55 \\
(10.11)\end{array}$ & 11.91 & $2=3=1>4 \# \#$ \\
\hline $\mathrm{VIQ}^{a}$ & $\begin{array}{l}90.80 \\
(13.05)\end{array}$ & $\begin{array}{l}93.60 \\
(13.33)\end{array}$ & $\begin{array}{l}100.94 \\
(13.80)\end{array}$ & $\begin{array}{l}112.49 \\
(16.19)\end{array}$ & 64.90 & $4>3>1=2 \# \#$ \\
\hline $\mathbf{P I Q}^{a}$ & $\begin{array}{l}95.60 \\
(13.22)\end{array}$ & $\begin{array}{l}96.65 \\
(13.36)\end{array}$ & $\begin{array}{l}102.08 \\
(14.94)\end{array}$ & $\begin{array}{l}109.15 \\
(14.77)\end{array}$ & 27.44 & $4>3>1=2 \# \#$ \\
\hline FSIQ $^{a}$ & $\begin{array}{l}91.11 \\
(12.24)\end{array}$ & $\begin{array}{l}92.19 \\
(13.01)\end{array}$ & $\begin{array}{l}100.86 \\
(13.59)\end{array}$ & $\begin{array}{l}110.98 \\
(13.70)\end{array}$ & 68.63 & $4>3>1=2 \# \#$ \\
\hline
\end{tabular}

$\#=\mathrm{p}<.05 ; \# \#=\mathrm{p}<.0005 ; \mathrm{CGI}=$ Conners' Global Index; CBCL att $=\mathrm{CBCL}$ attention subscale $; \mathrm{CBCL}$

anxdep $=$ CBCL anxiety depression subscale; RCMAS total = RCMAS total anxiety T score; $a$

$\mathrm{VIQ} / \mathrm{PIQ} / \mathrm{FSIQ}=$ verbal/performance/fullscale IQ raw scores; $b 4 \times 2 \chi^{2} ; *=$ in clinical range 


\section{TABLE 2}

Visuospatial working memory and spatial span in ADHD alone, ADHD and anxiety (ADHDANX), anxiety alone (ANX) and healthy control groups

\begin{tabular}{|c|c|c|c|c|c|c|}
\hline & $\begin{array}{c}1 \\
\text { ADHD } \\
N=163\end{array}$ & $\begin{array}{c}2 \\
\text { ADHDANX } \\
N=\mathbf{2 4 3}\end{array}$ & $\begin{array}{c}3 \\
\text { ANX } \\
N=69\end{array}$ & $\begin{array}{c}4 \\
\text { Controls } \\
N=116\end{array}$ & $\mathbf{F}$ & $\begin{array}{c}\text { Group } \\
\text { differences }\end{array}$ \\
\hline BSE total & $\begin{array}{l}43.35 \\
(16.54)\end{array}$ & $\begin{array}{l}45.08 \\
(17.77)\end{array}$ & $\begin{array}{l}37.88 \\
(16.33)\end{array}$ & $\begin{array}{l}29.84 \\
(16.79)\end{array}$ & 8.24 & $1=2>3>4 \# \#$ \\
\hline Strategy & $\begin{array}{l}36.04 \\
(4.16)\end{array}$ & $\begin{array}{l}36.20 \\
(5.28)\end{array}$ & $\begin{array}{l}34.57 \\
(6.12)\end{array}$ & $\begin{array}{l}33.19 \\
(5.19)\end{array}$ & 3.64 & $1=2>3=4 \#$ \\
\hline Span & $\begin{array}{l}5.32 \\
(1.49)\end{array}$ & $\begin{array}{l}5.20 \\
(1.48)\end{array}$ & $\begin{array}{l}5.95 \\
(1.51)\end{array}$ & $\begin{array}{l}6.45 \\
(1.30)\end{array}$ & 10.96 & $1=2<3<4 \# \#$ \\
\hline $\begin{array}{l}\text { Reaction time } \\
\text { (msec) }\end{array}$ & $\begin{array}{l}139739.36 \\
(3119.76)\end{array}$ & $\begin{array}{l}141672.78 \\
(2587.87)\end{array}$ & $\begin{array}{l}144176.43 \\
(4959.54)\end{array}$ & $\begin{array}{r}132144.53 \\
(4200.01)\end{array}$ & 1.54 & NS \\
\hline
\end{tabular}

$\#=\mathrm{p}<.05 ; \# \#=\mathrm{p}<.0005 ;$ BSE total = between search errors total raw score at different levels of difficulty $-3,4,6,8$ boxes on screen; Strategy = strategy raw score; Span = span raw score 


\section{FIGURE 1}

Mean number of Between Search Errors (BSE) at each level of difficulty on the spatial working memory task for ADHD alone (ADHD), ADHD and anxiety disorders (ADHDANX), anxiety disorders alone (ANX) and healthy control (HCP) groups.

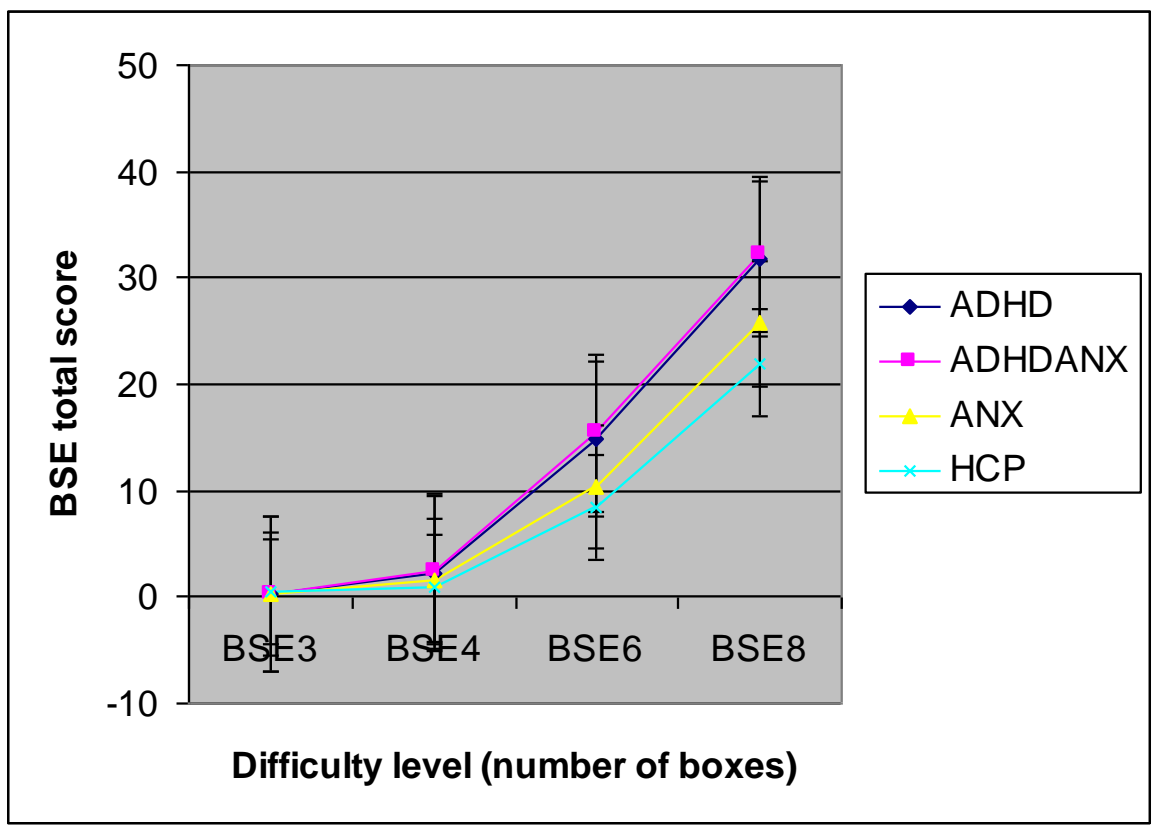


